\title{
Formación de hollín en la pirólisis de 1-butanol. Estudio eco-toxicológico
}

\author{
Ricardo Pernía, Tyler Pearson, Ángela Millera, Rafael Bilbao, María U. Alzueta \\ Grupo de Procesos Termoquímicos (GPT) \\ Instituto de Investigación en Ingeniería de Aragón (I3A) \\ Universidad de Zaragoza, Mariano Esquillor s/n, 50018, Zaragoza, Spain. \\ Tel. +34-876555451, e-mail: rpernia@unizar.es
}

\begin{abstract}
El trabajo realizado tiene como objetivo el estudio experimental de la formación de hollín a partir de la pirólisis de 1-butanol $\left(\mathrm{C}_{4} \mathrm{H}_{9} \mathrm{OH}\right)$ a distintas temperaturas $\mathrm{y}$ en condiciones de laboratorio controladas, así como la caracterización de las muestras de hollín obtenidas considerando sus características eco-toxicológicas.
\end{abstract}

\section{Introducción}

El biobutanol es uno de los biocombustibles más prometedores debido a sus superiores propiedades como combustible en comparación con los principales biocombustibles utilizados, bioetanol y biodiésel. Su mayor contenido energético (casi un $30 \%$ más que el etanol), su capacidad para mezclarse con gasolina y diésel, su menor riesgo de separación y corrosión y su resistencia a la absorción de agua, hacen que el butanol presente ventajas muy interesantes para su utilización, ya que además, los motores no requieren casi ninguna modificación.

Al mismo tiempo, es de gran importancia estudiar el biobutanol desde un punto de vista medioambiental, ya que al tratarse de un compuesto oxigenado puede ayudar a reducir las emisiones contaminantes de hollín, el cual se forma en puntos del motor donde existe déficit de oxígeno. El hollín está formado por pequeñas partículas sólidas que tienen la capacidad de introducirse en los pulmones y que pueden tener propiedades carcinogénicas [1].

En este contexto, el objetivo de este trabajo es el estudio de la formación de hollín en la pirólisis de 1-butanol a diferentes temperaturas, así como evaluar las características del hollín formado, en concreto su eco-toxicidad.

\section{Método experimental}

En el presente estudio se ha llevado a cabo la formación de hollín a partir de 1-butanol. Los experimentos se realizaron a presión atmosférica, a distintas temperaturas $1000,1050,1100,1150$ y $1200{ }^{\circ} \mathrm{C}$, y en un reactor de flujo de cuarzo con una zona de reacción de $45 \mathrm{~mm}$ de diámetro interno y $800 \mathrm{~mm}$ de longitud. El caudal total en todos los experimentos ha sido $1 \mathrm{~L}$ (STP)/min. El 1-butanol es alimentado mediante una bomba HPLC y calentado hasta $140{ }^{\circ} \mathrm{C}$ mediante una resistencia eléctrica para introducirlo en estado gaseoso al interior del reactor. Además, se alimenta nitrógeno para completar el caudal total. A la salida del reactor se interrumpe la reacción con una corriente de refrigeración que disminuye drásticamente la temperatura. La concentración de 1-butanol fue de $22500 \mathrm{ppm}$ en todos los experimentos. Al finalizar cada experimento se recoge el hollín formado y se cuantifica por pesada.

Para el análisis eco-toxicológico, se tomaron $50 \mathrm{mg}$ de las muestras de hollín obtenidas en los experimentos, las cuales fueron enviadas $y$ evaluadas en los laboratorios de DIFARMA de la Università degli Studi di Salerno. Las células usadas en el ensayo eco-toxicológico fueron células A549, células de adenocarcinoma de pulmón humano. Se realizaron tres tipos de ensayos: Un ensayo de viabilidad celular (ensayo MTT) en el que las células se trataron durante 24 horas con diferentes concentraciones en serie de partículas de hollín ( 0.5 $\mathrm{pg} / \mathrm{mL}$ hasta $1 \mathrm{ng} / \mathrm{mL}$ ), un ensayo de proliferación celular donde las células se tiñeron previamente con CFSE (éster succinimidílico de carboxifluoresceína, $1 \mu \mathrm{M})$ y se evaluaron a los 3 días del tratamiento, colorante que es útil para evaluar la proliferación celular, y un ensayo de liberación de citoquinas proinflamatorias, en el que las células se trataron durante 18-24 horas con partículas de hollín y las citoquinas liberadas se analizaron por medio del método ELISA [2].

\section{Resultados}

Se cuantificó la masa de hollín obtenidad en cada experimento y se calculó el rendimiento a hollín 
para cada temperatura como ( $\mathrm{g} \mathrm{C}_{\text {obtenido }} / \mathrm{g} \mathrm{C}_{\text {alimentado }}$ ), en $\%$. Los resultados obtenidos se muestran en la Tabla 1. Se puede observar como el rendimiento a hollín aumenta conforme aumenta la temperatura, lo que parece indicar que al aumentar la temperatura se favorecen las reacciones de pirólisis y, por lo tanto, aumenta la cantidad de hollín formado [3].

Los resultados de los ensayos eco-toxicológicos quedan recogidos en la Tabla 2 . Los ensayos de viabilidad mostraron que en ningún caso las muestras de hollín estudiadas provocaron muerte celular, mientras que los resultados del ensayo de proliferación indicaron que la muestra de hollín producida a $1000{ }^{\circ} \mathrm{C}$ fue la única en producir un incremento estadístico en la proliferación de células, en comparación al resto de muestras estudiadas. Asimismo, se analizó la liberación de cuatro citoquinas proinflamatorias (IL-1 $\alpha$, IL-1 $\beta$, IL-6, $\mathrm{TNF} \alpha$ ). Los resultados mostraron que ninguna de las muestras produjo un aumento estadístico en la liberación de citoquina IL-1 $\alpha$. Lo mismo ocurrió con la citoquina IL-1 $\beta$, la cual no mostró un aumento estadístico, salvo en el caso de la muestra de hollín a $1200^{\circ} \mathrm{C}$. Además, también se estudió la liberación de las citoquinas IL-6 y TNFa. En este caso, se observó para las muestras producidas a 1100,1150 y $1200^{\circ} \mathrm{C}$ una liberación significativa de IL-6, mientras que ninguna de las muestras estudiadas mostró un aumento estadístico en la liberación de citoquina $\mathrm{TNF} \alpha$.

\section{Conclusiones y trabajo futuro}

A partir del estudio experimental de formación de hollín en la pirólisis de 1-butanol, se ha observado un aumento del rendimiento a hollín conforme aumenta la temperatura.

Como conclusión de los análisis eco-toxicológicos, ninguna de las muestras indujo la muerte a las células. Además, sólo la muestra de hollín $1000^{\circ} \mathrm{C}$ provocó una proliferación celular significativa. Por último, se podría definir la muestra de $1200^{\circ} \mathrm{C}$ como pro-inflamatoria, en comparación al resto de muestras.

Este estudio se ha realizado con las muestras de hollín con PAHs adheridos a su superficie, se está estudiando la posibilidad de analizar por separado la eco-toxicidad de hollín y PAHs.

\section{Agradecimientos}

Los autores quieren expresar su gratitud al Gobierno de Aragón y al Fondo Social Europeo (grupo GPT), y al proyecto Waste2Fuels que ha recibido financiación de European Union's Horizon 2020 Research and Innovation Programme ( $\left.{ }^{\circ} 654623\right)$.

\section{REFERENCIAS}

[1]. World Health Organization (WHO), International Agency for Research on Cancer. IARC: diesel exhaust carcinogenic, Report 213. 2012.

[2]. HUGHES, D y MEHME, H. Cell Proliferation and Apoptosis. Series Advanced Methods. s.l.: CRC Press Taylor \& Francis Group, 2003.

[3]. VITERI. F., GRACIA, S., MILLERA, A., BILBAO, R., ALZUETA, M.U. Polycyclic aromatic hydrocarbons (PAHs) and soot formation in the pyrolysis of the butanol isomers. Fuel. 2017, vol. 197, pp. 348-358.

Tabla 1. Rendimientos de 1-butanol a hollín para cada temperatura.

\begin{tabular}{|l|c|c|c|c|c|c|}
\hline Temperatura $\left({ }^{\circ} \mathbf{C}\right)$ & $\mathbf{9 5 0}$ & $\mathbf{1 0 0 0}$ & $\mathbf{1 0 5 0}$ & $\mathbf{1 1 0 0}$ & $\mathbf{1 1 5 0}$ & $\mathbf{1 2 0 0}$ \\
\hline Tiempo (h) & 7 & 4 & 8 & 4 & 4 & 4 \\
\hline Masa C (g) & 0,02 & 0,57 & 4,37 & 2,28 & 2,76 & 3,70 \\
\hline Masa C total (g) & 20,30 & 11,60 & 23,20 & 11,60 & 11,60 & 11,60 \\
\hline Rendimiento (\%) & 0,09 & 4,96 & 18,82 & 19,68 & 23,80 & 31,93 \\
\hline
\end{tabular}

Tabla 2. Resultados eco-toxicológicos de las muestras de hollín de la pirólisis de 1-butanol.

\begin{tabular}{|c|c|c|c|c|c|c|c|}
\hline Hollín & $\begin{array}{l}\text { Muerte } \\
\text { celular }\end{array}$ & $\begin{array}{c}\begin{array}{c}\text { Proliferación } \\
\text { celular }\end{array} \\
\end{array}$ & IL-1 $\alpha$ & IL-1及 & IL-6 & TNFa & Tóxico \\
\hline 1-butanol $1000^{\circ} \mathrm{C}$ & NO & SI & NO & NO & $\mathrm{NO}$ & NO & NO \\
\hline 1-butanol $1050^{\circ} \mathrm{C}$ & NO & NO & NO & $\mathrm{NO}$ & $\mathrm{NO}$ & NO & NO \\
\hline 1-butanol $1100^{\circ} \mathrm{C}$ & NO & NO & NO & NO & SI & NO & NO \\
\hline 1-butanol $1150^{\circ} \mathrm{C}$ & $\mathrm{NO}$ & $\mathrm{NO}$ & $\mathrm{NO}$ & $\mathrm{NO}$ & SI & $\mathrm{NO}$ & $\mathrm{NO}$ \\
\hline 1-butanol $1200^{\circ} \mathrm{C}$ & $\mathrm{NO}$ & $\mathrm{NO}$ & $\mathrm{NO}$ & SI & SI & NO & PRO-INFLAMATORIO \\
\hline
\end{tabular}

Revista "Jornada de Jóvenes Investigadores del I3A", vol. 6 (Actas de la VII Jornada de Jóvenes Investigadores del I3A - 8 de junio de 2018). ISSN 2341-4790. 